\title{
ReSENHAS
}

REVIEWS

\section{O SISTEMA ÚNICO DE SAÚDE E SUAS DIRETRIZES CONSTITUCIONAIS}

\author{
Mônica de Almeida Magalhães Serrano \\ Editora Verbatim, São Paulo, 2009
}

Lucas Corrêa ${ }^{(*)}$

O livro é amplo em seu escopo e oferece uma diversidade de elementos necessários à compreensão crítica do contexto jurídico em que se desenvolve o direito à saúde no âmbito das políticas públicas sociais, no Brasil.

A obra está dividida em nove capítulos: no primeiro são analisados os direitos fundamentais, seu conceito, sua evolução e os princípios a eles aplicados quando de sua interpretação; no segundo, os direitos fundamentais sociais vem à baila de forma a reforçar a necessidade de sua efetiva implementação, com base nos ditames do texto constitucional brasileiro; no terceiro capítulo, são estudados os serviços públicos enquanto serviços viabilizadores da efetivação de direitos sociais, dentre eles, logicamente, o direito à saúde. Este direito, no quarto capítulo, é inserido na lógica de funcionamento do Sistema Único de Saúde (SUS) com vistas a sua efetivação na prática cotidiana dos serviços de saúde. No quinto capítulo, são analisadas as questões relativas ao planejamento orçamentário que, dentro dos parâmetros constitucionais e infra-constitucionais, oferece instrumentos hábeis para concretizar a finalidade pública na utilização do dinheiro público na implementação de políticas sociais. Em seguida, o princípio da reserva do possível é confrontado a eficácia dos direitos sociais. No sétimo e oitavo

(*) Advogado, especialista em Políticas de Saúde, Financiamento e Planejamento pela London School of Hygiene and Tropical Medicine e pela London School of Economics e mestre em Direito Social e Direito da Saúde pela Université Paris X - Nanterre. E-mail: <lhcorrea5@ hotmail.com>. 
capítulos se constata a existência, na ordem constitucional brasileira, de um direito público subjetivo à saúde que faculta ao cidadão a possibilidade de exigir seu direito à saúde perante o judiciário. O nono capítulo conclui o livro sintetizando o que foi abordado de modo a ressaltar a judicialização na saúde como etapa do processo de "aperfeiçoamento do estado democrático brasileiro."

No decorrer do texto, a autora mostra que dada à evolução histórica do direito à saúde e o modo como ele foi inserido na Constituição Federal brasileira de 1988, a realização da saúde, enquanto direito social fundamental, portanto de eficácia plena e aplicabilidade imediata, deve ser a finalidade de toda política pública e de toda ação emanada do poder público, em todas as suas esferas. Tanto porque o direito à saúde guarda íntima relação com o direito à vida, direito inalienável e indisponível. Nesse contexto, a prestação do serviço público de saúde, em todos os seus aspectos, é de responsabilidade do Estado cuja missão precípua é a de proporcionar as condições mínimas para que a população de seu território possa viver dignamente e exercer sua cidadania de forma integral. Essas condições mínimas devem ser proporcionadas pela implementação dos serviços públicos que tem, justamente, a finalidade de concretizar os direitos sociais elencados na carta maior. Para tanto, o zelo com a utilização do erário público é fundamental; a criação de mecanismos de controle e de fiscalização, tanto institucional quanto popular, bem como a de mecanismos de gestão e planejamento mostram a importância do bem gerir e do bem aplicar o dinheiro público. Não fazê-lo, em teoria, significa não efetivar os direitos sociais fundamentais, sendo assim passível de questionamento judicial posto que a sua implementação é direito público subjetivo de toda e qualquer pessoa. Sustenta a autora que o Poder Judiciário, nesse diapasão, é órgão democratizante e incitador da concretização de políticas públicas sociais e, em via de consequência, de efetivação de direitos de segunda geração, contribuindo, em última análise, para a construção de uma sociedade democrática.

Revela-se muito interessante a forma como a autora encadeia as ideias apresentadas, de maneira que, a figura do gestor público ganha relevo fundamental no processo de efetivação dos direitos sociais, pautado por regras que, em teoria, se obedecidas, levam à concretização desses direitos. Como é sabido, o gestor somente pode fazer o que Ihe faculta a lei. Inicialmente, no entanto, em termos técnicos, é difícil passar sem questionamentos a crítica que a autora tece aos gestores quanto à ineficiência do emprego do erário público na prática dos serviços de saúde, enquanto política social, inviabilizando a concretização do direito à saúde. Cabe também uma reflexão acerca da própria eficiência das regras administrativas que logicamente regem a atividade dos gestores públicos e que, portanto, serviriam para desencadear na efetivação de direitos sociais.

A literatura internacional no campo da economia da saúde aborda o tema da eficiência com cautela pela existência de variadas noções do que 
ela venha a ser ${ }^{(1)}$. Além de uma concepção funcionalista, onde se encontram três tipos de eficiência - a técnica, a alocativa e a econômica -, existe uma concepção político-filosófica do termo que também se desdobra em alguns sub-tipos. Apesar de a crítica feita pela autora se referir, aparentemente, à primeira concepção que caminha na linha da definição do princípio da eficiência do direito administrativo pátrio, esta não vai sem a segunda, que a abarca. Assim, para citar apenas dois exemplos dos sub-tipos dessa concepção ampla: a eficiência, tal como entendida por John Rawls na sua "Theory of Justice"(2) preconiza que cada unidade de recurso utilizado no sistema deve ter como resultado a melhoria da situação dos menos favorecidos de modo a, gradativamente, reduzir a desigualdade social existente entre os mais favorecidos e os mais necessitados, mesmo que isso signifique a piora da situação dos mais abastados; a eficiência de Paretto, Paretto efficiency ${ }^{(3)}$, por outro lado, preconiza que cada unidade do recurso empregado no sistema o deve ser de modo a não permitir que os mais favorecidos sejam de qualquer forma desfavorecidos. Verifica-se, assim, que a questão da eficiência (em seu sentido amplo) se refere, em verdade, à escolha, de cunho eminentemente político (e não partidário), pela qual se busca definir os contornos do pacto social que determina a medida da solidariedade entre os que precisam mais e os que precisam menos dentro de um território.

Raramente essa opção é feita de forma transparente no Brasil, apesar das claras imposições constitucionais acerca da implementação de direitos sociais, posto que fundamentais. Fora da seara das políticas sociais, praticamente esquecidas a partir de 1999, verifica-se que o grau de solidariedade é definido atualmente quando se discute, principalmente, o rumo das políticas externa e monetária que, logicamente, interessam aos atores economicamente relevantes ${ }^{(4)}$. Nesse cenário, o gestor público de uma secretaria de saúde de um município qualquer do país que tente implementar uma política de saúde equitativa com vistas à integralidade da atenção, em obediência a todos os ditames constitucionais e legais, se vê indo de encontro ao próprio enfoque (ou a falta de enfoque) dado (a) à forma como se dá a implementação das políticas públicas pelo ente federado, reflexo do pacto social concernente à solidariedade.

Isso se reflete, de forma prática e sensível, no emprego de recursos públicos, principalmente, da esfera federal. A palavra "principalmente" empregada

(1) MCGUIRE, A.; FENN, P., MAYHEW, K. The economics of health care: an assessment. In: Providing health care: the economics of alternative systems of finance and delivery. Oxford, UK; Oxford University Press, 1991. p. 5-45.

(2) RAWLS, J. A theory of justice, Harvard: Harvard University Press, 2003. 560 p.

(3) MCGUIRE, A.; FENN, P.; MAYHEW, K. op. cit., p. 5-45.

(4) COSTA, N. R. da. Social protection in Brazil: universalism and targeting in the FHC and Lula administration. Ciência \& Saúde Coletiva, v. 14, n. 3, p. 693-706, 2009. 
na frase anterior se justifica porque a complementaridade e a suplementaridade das ações (de implementação de políticas públicas) entre os entes federados - apesar de a co-responsabilidade entre eles ser explícita no texto constitucional —, acabam ficando a mercê de interesses político-partidários que inviabilizam a interação produtiva (porque em prol dos cidadãos) entre, notadamente, estados e municípios. Nesse contexto, se justifica a redução cada vez mais pronunciada dos repasses financeiros na saúde, dos estados em direção aos municípios(5).

Assim, tentar corrigir as imperfeições da macroestrutura política pelo nível local é, no mínimo, em jargão corriqueiro, pedir demais. Não se discute a necessidade da utilização adequada do recurso público, fazendo uso de todas as ferramentas de planejamento e técnicas administrativas pelo gestor no nível local, mas não se deve esperar somente dele a mudança social preconizada pela Carta Maior. O gestor local vive e trabalha dentro de um contexto que não apenas se resume à limitação de recursos financeiros, de forma alguma compensada pelos estados, mas que também é fruto da influência das opções políticas e sociais colocadas em prática a partir de uma esfera superior e, também, dos sistemas de valores culturais existentes, de uma dada realidade.

Entretanto, isso não reafirma a incapacidade do gestor local modificar a realidade em que vive, mas procura chamar atenção ao fato de que a obediência às próprias regras jurídicas, enquanto fruto de uma conjuntura política, econômica, social e cultural, como as de direito administrativo, pode levar a um efeito contrário ao que a própria Constituição preconiza em termos de efetivação de direitos sociais. Hoje, um gestor que obedece a todos os ditames legais, não tem assegurada uma administração eficiente e realizadora de direitos sociais.

Cabe aí, portanto, uma reflexão sobre a propagação e a consolidação dessas opções políticas e sociais no próprio ordenamento jurídico pátrio que, ao mesmo tempo, procura "amarrar" a atuação do gestor no sentido de fazê-lo necessariamente alcançar um fim socialmente relevante, qual seja a implementação dos direitos fundamentais, mas cuja efetivação está longe de ser garantida pela mera observação dessas normas no desenvolvimento de suas atividades. Em realidade, essas normas não se conformam às necessidades crescentes de agilidade e flexibilidade exigidas por setores, como é o caso do setor saúde, onde existe um elemento predominante de incerteza.

Nesse sentido, aliado à argumentação anterior, é preciso que se desenvolva uma nova forma de encarar a aplicação do direito. Não se trata mais apenas da subsunção de um fato à norma, próprio do direito codificado do

(5) COLLINS, C.; ARAUJO, J.; BARBOSA, J. Decentralising the health sector: issues in Brazil, Health Policy, v. 52, n. 2, p. 113-127, 2007. 
século XIX. Trata-se de entender o contexto político, econômico, social e cultural onde se pretende aplicada a norma. Assim, um judiciário despreparado para enfrentar as intricadas questões de violação de direitos individuais no contexto da implementação de políticas públicas que ocorrem dentro desse cenário amplo e complexo, exige do aplicador da lei, nos dizeres de Boaventura de Souza Santos ${ }^{(6)}$, "um conhecimento social, cultural, para que haja um entendimento de que as sociedades são [...] muito desiguais."

Nesse contexto de desigualdade que torna ainda mais imperiosa a implementação de políticas públicas sociais, a judicialização, tal como se apresenta hoje, apesar de consistir em passo importante rumo a uma nova forma de democracia, mais justa, está longe de ser satisfatória e consistir em estratégia sustentável para a efetivação de direitos coletivos capaz de influenciar mudanças de cunho cultural, social e político formando cidadãos, de que tanto precisa esse país.

Nesse sentido, a autora poderia ter lançado, apesar de esse não ter sido esse o objeto do trabalho, um olhar mais generoso não só ao papel do gestor mas, principalmente, ao do gestor que atua no âmbito municipal quanto à implementação de uma política de Estado como o SUS; uma vez que este gestor fica à mercê de uma política que define recursos para políticas públicas de forma pouquíssimo técnica. Tal fato implica na vinculação da aplicação desses recursos a questões pré-determinadas, vindas "do alto" e que, no final das contas, encontra o sério risco de estar desvinculada das necessidades sociais locais, inviabilizando, assim, a efetivação de direitos.

No entanto, o livro tem qualidade importante e indiscutível posto que revela, de forma clara, objetiva e engajada, o cenário e a maneira como deveria ser encarada não apenas a saúde, mas todos os direitos sociais no país. Trata-se de obra muito relevante e de leitura obrigatória a todos os que atuam no setor saúde no país, principalmente na administração pública.

\section{REFERÊNCIAS BIBLIOGRÁFICAS}

Boletim do CEBES de 29 de janeiro de 2010. Disponível em <http:// www.cebes.org.br/default.asp?site_Acao $=$ mostraPagina\&paginald $=134 \& \mathrm{~m}$ Noti_Acao=mostraNoticia\&noticiald $=2135>$ [Entrevista].

Bisol, J. Judicialização desestruturante: reveses de uma cultura jurídica obsoleta In: O Direito Achado na Rua: Introdução crítica ao direito à saúde. COSTA et al. (organizadores), Brasília: CEAD/UnB, 2008.

(6) Entrevista publica no Boletim do CEBES de 29 de janeiro de 2010. Disponível em <http://www.cebes.org.br/ default.asp?site_Acao=mostraPagina\&paginald=134\&mNoti_Acao=mostraNoticia\&noticiald=2135> 
COLLINS, C., ARAUJO, J., BARBOSA, J. Decentralising the health sector: issues in Brazil, Health Policy, v. 52, n. 2, p. 113-127, 2007.

COSTA, N. R. da. Social protection in Brazil: universalism and targeting in the FHC and Lula administration. Ciência \& Saúde Coletiva, v. 14, n. 3, p. 693-706, 2009.

MCGUIRE, A.; FENN, P., MAYHEW, K. The economics of health care: an assessment. In: Providing health care: the economics of alternative systems of finance and delivery. Oxford, UK; Oxford University Press, 1991. p. 5-45.

RAWLS, J. A theory of justice, Harvard: Harvard University Press, 2003. 560 p. 